\title{
Niobium addition effect in molds at last cooling step on EN-GJL250 gray cast iron: Microstructural changes and electrochemical behavior
}

\author{
${ }^{*}$ M. O. Azzoug ${ }^{1}$, N. Boutarek-Zaourar', D. Aboudi', N. Madaoui ${ }^{2}$, E. Mossang ${ }^{3}$, and S. Chentouf ${ }^{4}$ \\ 1. Laboratory of Materials Technology, Faculty of Mechanical Engineering and Process Engineering, University of Science and Technology \\ Houari Boumediene, B.P. 32 El Alia, 16111 Algiers, Algeria \\ 2. Ionized Media Division, Center for Advanced Technology Development CDTA, Cité du 20 August 1956, Baba Hassen, BP N 17, Algiers, Algeria \\ 3. NEEl Institute, National Center for Scientific Research, 25, rue des Martyrs, BO 166, 38042, Grenoble Cedex, France \\ 4. Department of Mechanical Engineering, School of Technology Superior, 1100 Notre-Dame Street West, Montreal, Quebec H3C 1 K3, Canada
}

\begin{abstract}
The purpose of this study was to determine the impact of niobium addition as an inoculation element on the microstructure and electrochemical properties of EN-FGL250 gray cast iron. Niobium additions are in a powder form and have a $0.5 \mathrm{~mm}$ particle size at dfferent proportions of $1 \mathrm{wt} . \%$ and $3 \mathrm{wt} . \%$. The addition was done during casting of the metal in the mold at the last cooling step of the melt cast iron. These additions have a significant impact on the phenomenon of solidification as the metal powder deposited in the sand molds creates new centers of germination and absorbs a lot of heat. The cooling rate directly affects the microstructure and electrochemical behavior. This is confirmed by SEM observations and electrochemical tests. Furthermore, the addition of niobium transforms the microstructure of gray cast iron from cellular structure into totally dendritic structure. As a consequence, the niobium addition affected the shape and size of graphite, thus considerably reducing the corrosion current density by increasing the polarization resistance $R_{\mathrm{p}}$.
\end{abstract}

Key words: Lamellar cast iron; microstructure; lamellar graphite shapes; niobium; inoculation; corrosion resistance

CLC numbers: TG143.2 Document code: $\mathrm{A}$

Article ID: 1672-6421(2018 03-228-08

\begin{abstract}
T $t$ is well established that the variety of applications Lof cast iron is attributed to the presence of chemical elements in the solid solution as interstitial or substitutional form, such as so-called addition elements $\mathrm{Ni}, \mathrm{Cu}, \mathrm{Ti}, \mathrm{Cr}, \mathrm{V}$ and $\mathrm{Nb}^{[1-4]}$, and inoculation elements $\mathrm{Al}, \mathrm{Si}, \mathrm{Ca}, \mathrm{Sr}, \mathrm{Mn}, \mathrm{Zr}, \mathrm{P}, \mathrm{Sn}$ and $\mathrm{Ce}^{[5-7]}$.

In the foundry, additions are done by controlling the

\footnotetext{
*M. O. Azzoug

Male, born in 1979, Teacher (assistant master) at University of Sciences and Technology Houari Boumedienne Algiers, Algeria, also Ph.D student in Materials Science and Engineering. He is currently working on the development of a surface treatment process for gray cast irons directly in the manufacturing stage of parts without resorting to conventional (physical or chemical) surface treatments by metal deposition process or surface treatment. The influence of additions in the gray cast iron of various metallic materials, especially those of the fifth and sixth columns of the periodic table, is also part of the his research work field of interest. He is interested in the impact that these elements can have on the microstructure, mechanical and chemical change of gray cast iron.

E-mail: kassiazzoug@gmail.com
}

Received: 2018-01-04; Accepted: 2018-04-02 chemical composition of the melt rather than equivalent carbon, alloying elements and inoculation products. The minor additions of alloying elements for their affinities to carbon can be used to improve the mechanical properties of the cast iron mainly by the formation of $\mathrm{M}_{7} \mathrm{C}_{3}, \mathrm{M}_{3} \mathrm{C}$ and $\mathrm{MC}$ type carbides. Filipovic et al. ${ }^{[4]}$ have shown that variable proportions of additions of niobium and vanadium to the hypoeutectic white cast iron containing 19\% chromium modify its microstructure and affect its wear and hardness properties. Kesseri et al. ${ }^{[3]}$ have also shown that the addition of niobium in chromium-rich cast irons improves the mechanical properties by the formation of MC-type niobium carbides.

Similarly, the inoculation elements have a strong affinity to oxygen and sulfur ${ }^{[8-11]}$. Thus, oxides and sulphides of a homogeneous or heterogeneous nature formed in the melt give the graphite nucleation sites ${ }^{[12-}$ ${ }^{14]}$. Some authors suggested that the $\mathrm{Mn} / \mathrm{S}$ ratio affects the nucleation and morphology of graphite ${ }^{[15,16]}$. Other authors ${ }^{[17,18]}$ indicated that the inoculations elements 
are in relation to the nucleation process and morphological transformations of graphite. The latter is dependent on the tensile strength of the cast iron (cracking sites) and the corrosion behavior in some corrosive environments ${ }^{[7,10,19-22]}$.

Therefore, it is well known that corrosion is the predominant mechanism during the deterioration of cast iron in service, particularly in the water transport sector where they are prone to various forms of corrosion ${ }^{[23,24]}$. Many studies have been conducted to detect the mechanisms and factors responsible for degradation. Mohebbi et al. ${ }^{[25]}$ found that localized corrosion (pitting) is the main form of corrosion in cast iron water pipes. Mehra et al. ${ }^{[19]}$ investigated the variation in corrosion rate and corrosion current density of gray cast iron as a function of immersion time in various salt solutions. These authors found that the $\mathrm{NaCl}$ solution is the most corrosive to cast iron.

Lunarska $^{[7]}$ studied the effect of the graphite form on corrosion of gray cast iron in acid phosphoric $\left(\mathrm{H}_{3} \mathrm{PO}_{4}\right)$. He concluded that the vermicular form of graphite is beneficial to the mechanical and tribological properties. Nevertheless, it can accelerate corrosion of cast iron by erosion. Tronstad and Sejested ${ }^{[26]}$ studied the influence of sulfur content on the electrochemical behavior of carbon steel in $2 \mathrm{~N} \mathrm{NaCl}$ solution. They found that an anodic attack is immediately triggered around sulphide inclusions in the metal. However, on the metal surface there were also inactive sulphides. These authors suggested that the active centers are sulphides of iron and manganese $(\mathrm{Mn}, \mathrm{Fe}) \mathrm{S}$. The dissolution of the metal seems to be caused by agglomeration of $\mathrm{Cl}^{-}$ions in these inclusions. Miyata et al. ${ }^{[27]}$ studied the anodic dissolution of spheroidal graphite cast iron according to the

\section{Materials and methods}

The samples used in the present study were made by permanent model (wood pattern) casting process which includes a manual sand casting operation. The samples casting was performed by using the silico-clayey sand molds at El Harrach foundry (ALFEL, Algeria) (Fig.1a). The niobium introduced into the mold footprint is a ferro-niobium powder. Its nominal composition is shown in Table 1 . The niobium powder was ground and sieved to the particle size of $0.5 \mathrm{~mm}$ (Fig. 1b). The molten metal in the cupola was introduced into the molds via a pocket (Fig. 1c). The samples used in this work are shown in Fig.1d.

The chemical composition of samples was determined by a spark emission spectroscopy type MetalLab75-80J. The overall chemical composition of the cast iron is summarized in Table 1, which takes into account the combined influence of carbon and silicon by the formula Equation (1) ${ }^{[9]}$ :

$$
\mathrm{C}_{\mathrm{eq}}=\% \mathrm{C}+1 / 3(\% \mathrm{Si}+\% \mathrm{P})
$$

The metallographic characterization of the samples was performed by a scanning electron microscopy (SEM) JEOL 35X model coupled with the energy dispersive spectrometry (EDS) EDAX model. Phase identification was performed by XRD [(D8 DISCOVER, diffract Suite, copper anode $(\lambda=1.54), 2 \theta=20^{\circ}$ $120^{\circ}(0.02)$, spot $\left.\left.2 \mathrm{~mm}\right)\right]$ with a point-to-point sweep from the outer surface to volume of a $2 \mathrm{~mm}$ pitch. The electrochemical studies were performed by using stationary electrochemical techniques (the plot of the corrosion potential abandonment curves, potentiodynamic, linear polarization resistance, Tafel density of cementite lamellae and ferrite (pearlitic matrix) in sulfuric acid solutions. They showed that there was no difference in the anodic dissolution reaction mechanism between pure iron and spheroidal graphite iron. In addition, the anodic current density is independent of the density of the pearlitic matrix. As a result, the acceleration of anodic dissolution at the interfaces between the ferrite/cementite lamellae is negligible.

This work aims to study the influence of the added niobium (addition and inoculate element), in a powder form with a $0.5 \mathrm{~mm}$ grain size at the proportions of $1 \mathrm{w} . \%$ and $3 \mathrm{wt} . \%$, on the microstructure and corrosion behavior of EN-GJL250 gray cast iron during the metal casting in the mold. The source of these additions is ferroalloys. The originality of this work concerns the niobium addition in the last step of cooling of the melt cast iron in comparison with the traditional method where the addition of elements is made in the melt ${ }^{[5,14]}$.
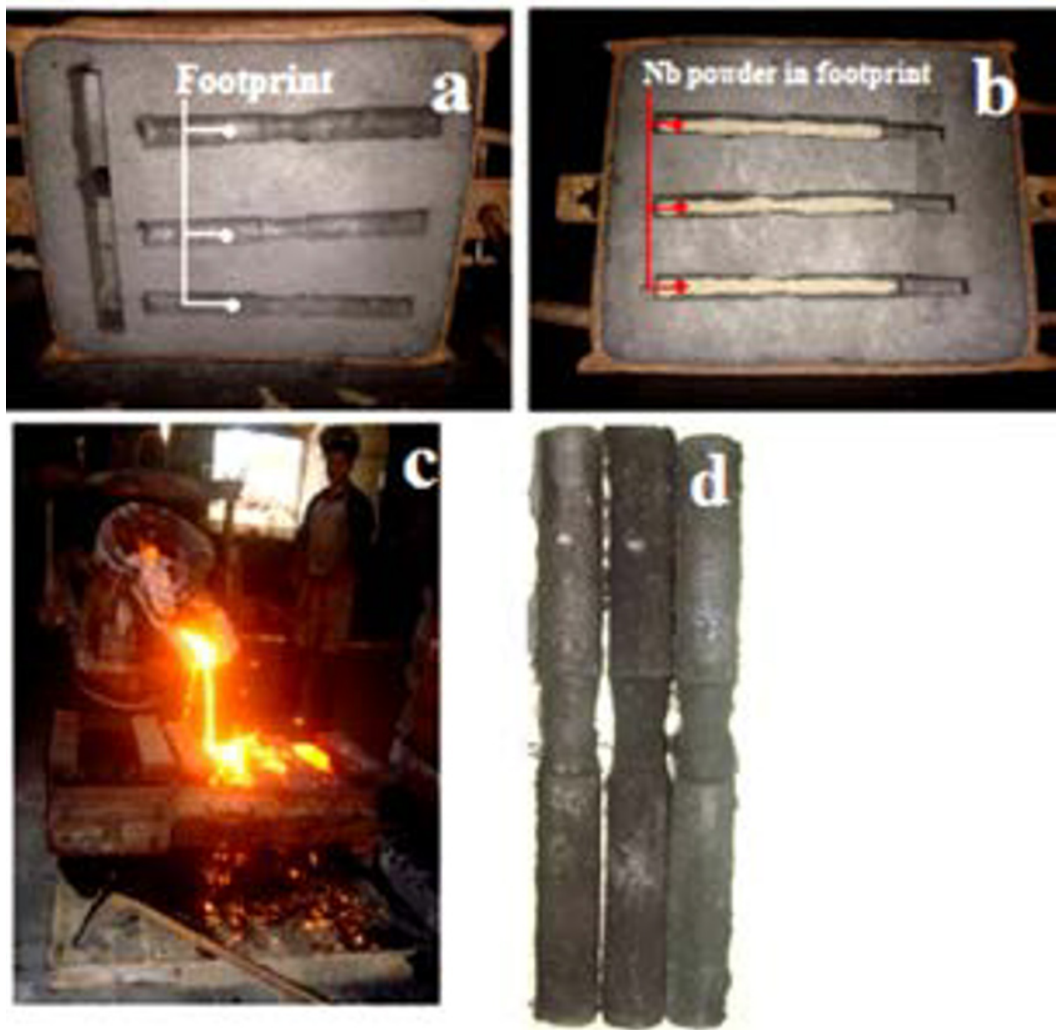

Fig. 1: Silico-clayey sand molds samples preparation : (a) half upper mold for tensile test specimens, (b) niobium powder introduced into the half lower mold footprint, (c) molten metal introduced into the molds and (d) prepared samples 
Table 1: Chemical analysis of EN-GJL 250 cast iron and Fe-Nb powder (wt.\%)

\begin{tabular}{|c|c|c|c|c|c|c|c|c|c|c|c|c|c|}
\hline & & $\mathrm{Fe}$ & C & Si & Mn & $\mathbf{P}$ & s & $\mathrm{Cr}$ & $\mathrm{Cu}$ & $\mathrm{Nb}$ & Al & $\mathrm{Ta}$ & $\mathrm{Pb}$ \\
\hline \multirow{2}{*}{ EN-GJL 250} & $\begin{array}{l}\text { Percentage } \\
\text { referred }\end{array}$ & 93.88 & 3.15 & 1.90 & 0.64 & 0.31 & 0.12 & - & - & - & - & - & - \\
\hline & $\begin{array}{l}\text { Percentage } \\
\text { analyzed }\end{array}$ & 93.80 & 2.97 & 1.93 & 0.6 & 0.19 & 0.09 & 0.19 & 0.23 & - & - & - & - \\
\hline \multicolumn{2}{|c|}{ Fe-Nb powder } & 30 & 0.2 & 3 & - & 0.25 & 0.15 & - & - & 64.08 & 2 & 0.2 & 0.12 \\
\hline
\end{tabular}

slopes plots) in a $3.5 \mathrm{M} \mathrm{NaCl}$ solution. The electrochemical tests have been achieved by an electrochemical chain composed of: a cylindrical electrochemical cell Pyrex glass which allows the introduction of the working electrode, the reference electrode saturated calomel (SCE), the auxiliary electrode, the bubbler and thermometer, and a potensiostat-galvanostat PARSTAT 4000 model which is connected to a data processing unit composed of a computer provided with corrosion versa Studio software. This latter allows the electrochemical parameters calculation and the electrochemical speed evaluation. Temporal tracking of the corrosion potential has a two-fold objective: first, it helps to have a primary idea about the surface behavior in corrosive environments (corrosion, formation of a passive layer); secondly, it determines the time required to obtain steady and essential potentiodynamic plots.

\section{Metallographic analyses}

\subsection{Matrix microstructure and eutectic cells of gray cast iron EN-GJL250}

Figure 2 shows SEM-BSE micrographs at low magnification of the samples from EN-GJL250 gray cast iron without and with the powder niobium $(\sim 0.5 \mathrm{~mm})$ addition. The proportions of niobium are respectively $1 \mathrm{wt} . \%$ and $3 \mathrm{wt} \%$. The niobium powder was deposited on the surface of the lower footprint of the molds (Fig. 1b).

It is accepted that the chemical composition in dependence on the cooling mode has a strong influence on the structure of the gray cast iron ${ }^{[9]}$. At low magnification (Fig. 2), the structural appearance of the gray cast iron without addition niobium is in the cellular form of average size of about 310 $\mu \mathrm{m}$. Eutectic colonies are surrounded by eutectic cells with a large intercellular space. However, the addition of niobium significantly modifies the structure. At $1 \mathrm{wt} . \% \mathrm{Nb}$, the average diameter of the eutectic cells is $159 \mu \mathrm{m}$, and the intercellular space of the eutectic colonies is reduced. At $3 \mathrm{wt} . \% \mathrm{Nb}$, the structure of the gray cast iron becomes completely dendritic.

This microstructural evolution is a consequence of the solidification process of gray cast iron under technical parameters such as the melt chemistry, the inoculation practice, the holding temperature, as these mainly affect the rate of cooling and the state of nucleation below the eutectic ${ }^{[28,29]}$. Under a non-equilibrium supercooling, the liquid of noneutectic composition can generate a quasi-eutectic structure. The latter results directly from supercooling. During the rapid
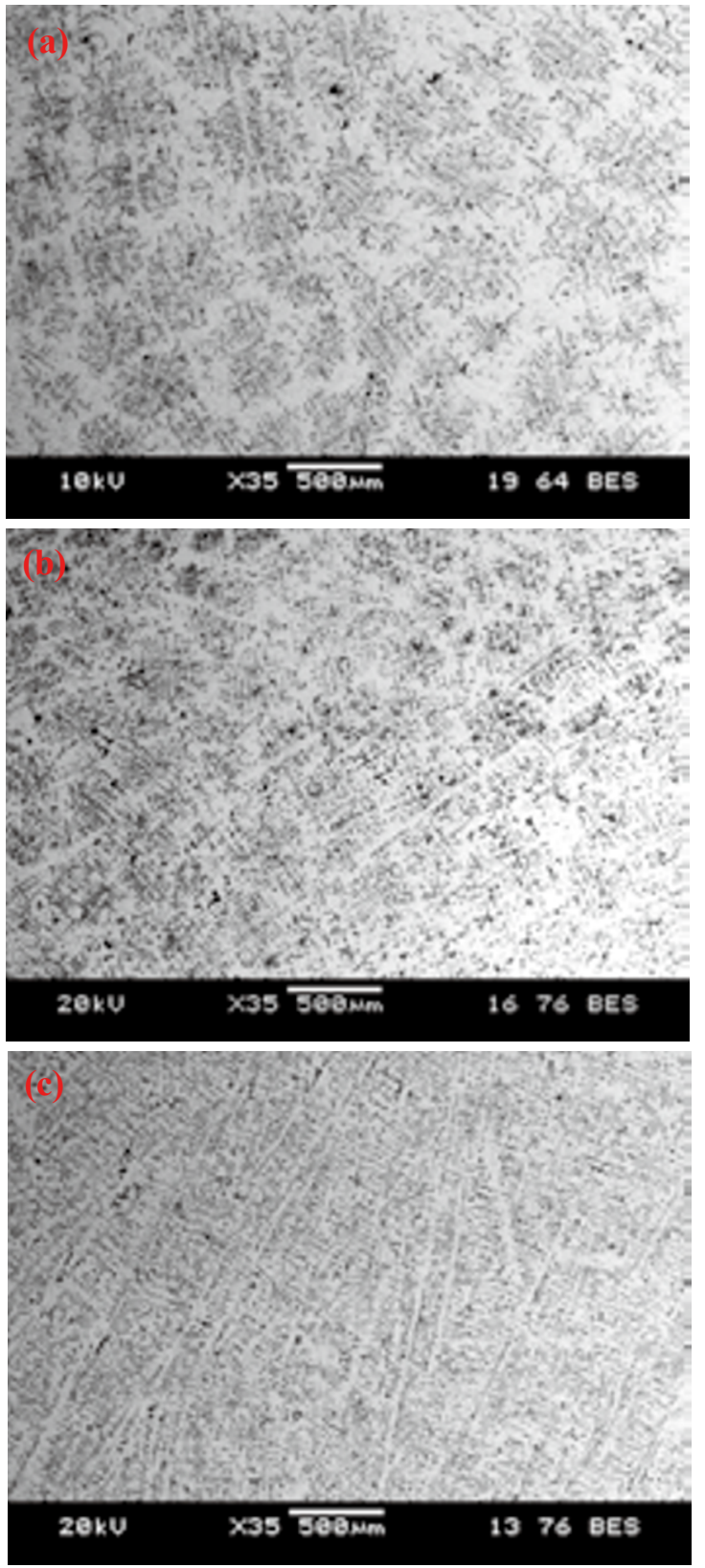

Fig. 2: SEM-BSE micrographs of samples from EN-GJL -250 gray cast irons: (a) without addition, (b) with $1 \mathrm{wt} . \% \mathrm{Nb}$ and (c) with $3 \mathrm{wt} . \% \mathrm{Nb}$

cooling below the equilibrium temperature of the eutectic, the supercooling of the liquid phase of the austenite $\left(\gamma_{\mathrm{Fe}}\right)$ and graphite $(G)$ is different. Due to its high melting temperature $\left(2,862{ }^{\circ} \mathrm{C}\right)$, the graphite has a supercooling higher than that of 
austenite $\left(\delta_{\mathrm{Fe}} \rightarrow \gamma_{\mathrm{Fe}}, 1,394{ }^{\circ} \mathrm{C}\right)$. This causes a different rate of growth of the phases, leading to an increase in the quasi-eutectic region. In the Fe-C system (Fig. 3), the quasi-eutectic region is diverted to the non-metallic constituent phase $(\mathrm{G})$. In addition to supercooling, due to fluctuations in concentration and different diffusion rates, the phase with the lowest melting point $\left(\gamma_{\mathrm{Fe}}\right)$ is the easiest to germinate and the growth rate is the highest.

The kinetics of solidification of the eutectic liquid depends both on the supercooling temperature and on the composition of the liquid ${ }^{[30-32]}$. According to studies conducted by Jiyang Zhou ${ }^{[33]}$ on the solidification of gray cast iron, the solidification of the supercooled hypoeutectic liquid below the liquidus begins with nucleation of the austenite. At lower temperatures, dendrites with low carbon levels grow in the liquid and generate the modification of the liquid composition according to the liquidus (Fig. 3, path 1-2). During cooling, the supercooled liquid below the eutectic point is located in the right of the quasi-eutectic region. The dendrites of the austenite are then surrounded by liquid carbon, which leads to the nucleation of graphite. The liquid slides in the quasi-eutectic zone (Fig. 3, path 2-3), and eutectic crystallization occurs (Fig. 3). The solidification structure comprises eutectic cells, austenite and dendrites. In addition to the conditions mentioned above, it has been proved that the intake of some chemical elements such as titanium and vanadium can increase the number and length of dendrites ${ }^{[14,34]}$. In our case, the transition from a cellular structure to a completely dendritic structure (Fig. 2b, 2b and 2c), is probably due to niobium effect. This can be attributed to the formation of niobium carbides $\left(\mathrm{Nb}_{2} \mathrm{C}\right.$, $\mathrm{NbC})$ and sulfides $(\mathrm{Mn}, \mathrm{Fe}) \mathrm{S}$.

\subsection{Graphite morphology}

As indicated in the previous section, the solidification of eutectic liquid occurs according to a growth coupled mode, where the formation of graphite and austenite occurs simultaneously in

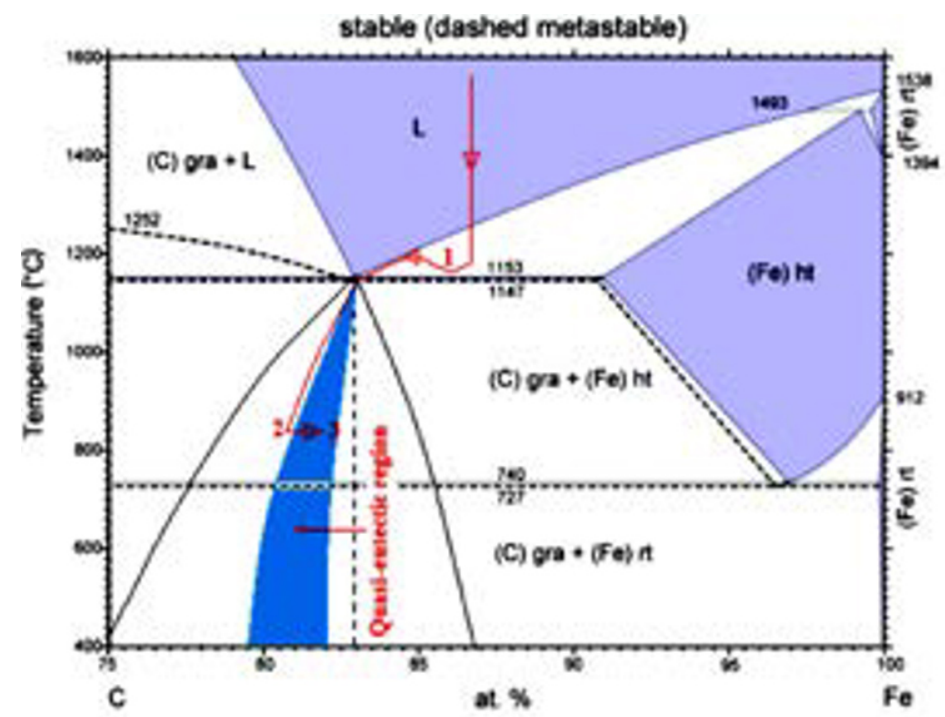

Fig. 3: Superimposed Fe-C (graphite) and $\mathrm{Fe}^{-} \mathrm{Fe}_{3} \mathrm{C}$ phase non-equilibrium solidification process of cast iron: the blue area represents the quasi-eutectic region and the red line represents the cooling path [JIY09] the interdendritic liquid. Thus, the mode of eutectic formation affects the shape, length, distribution, percentage and type of graphite lamellae. This certainly affects the physico-chemical properties of the cast iron. At medium magnification, the samples of the gray cast iron without and with the addition of niobium are shown in Fig. 4. The predominant graphite form in the cast iron without addition is straight lamellar (Fig.4a). However, the size and distribution of graphite are interdependent with the size of eutectic cells. At the outline of the cells, the mean graphite length is $45 \mu \mathrm{m}$, whereas inside the cells, the graphite is in a fragmented form with an average length $\leqslant 5 \mu \mathrm{m}$. Globally, the graphite is grouped in rosettes of any orientation. This arrangement of graphite is of type (B). According to some authors ${ }^{[5,14]}$, in cast iron whose chemical composition is near to eutectic, this type of graphite is formed with low supercooling and growth rate in large eutectic cells.
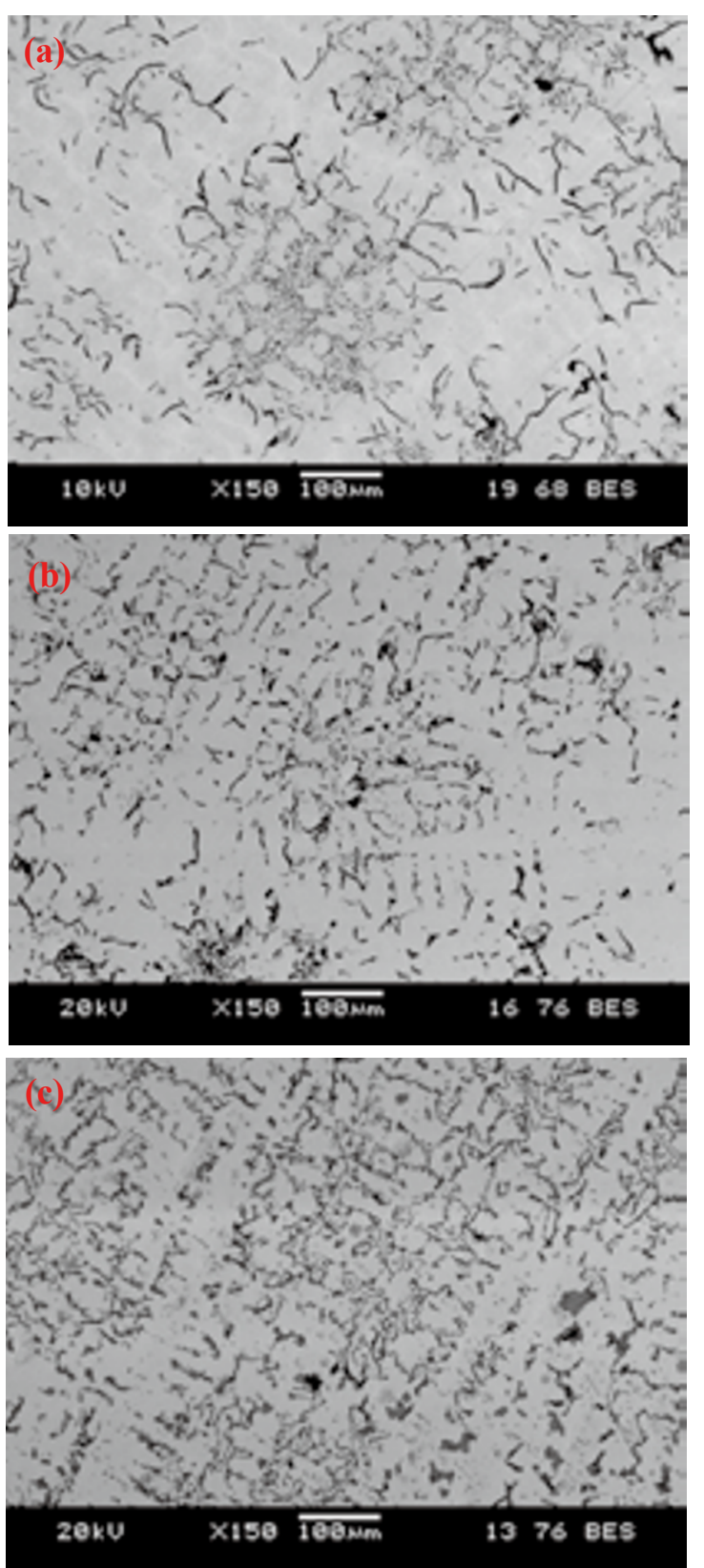

Fig. 4: SEM-BSE micrographs of samples from EN- GJL 250 gray cast: (a) without addition, (b) with $1 \mathrm{wt} . \%$ $\mathrm{Nb}$, and (c) with $3 \mathrm{wt} . \% \mathrm{Nb}$ 
At 1 wt.\% of niobium (Fig. 4b), the graphite lamellae exist in two forms: vortex and straight. Besides, for the medium length of graphite which has decreased to $25 \mu \mathrm{m}$, its arrangement has also been modified. Two types of graphite then subsist: type $\mathrm{B}$ rosettes of any orientation have been preserved, and type D represents an interdendritic segregation of graphite with any orientation.

At 3 wt. $\%$ of niobium (Fig. $4 \mathrm{c}$ ), the graphite lamellae have a straight shape. Nevertheless, there is co-existence of very thin lamellae approximately $15 \mu \mathrm{m}$ long, with thicker lamellae with an average length of $25 \mu \mathrm{m}$. However, the type of graphite is also modified to type $\mathrm{E}$, and the inclusions of graphite with interdendritic segregation then have privileged orientations.

According to some authors ${ }^{[6,35-37]}$, the morphological change of type B graphite to type $\mathrm{E}$ is governed by the supercooling rate. So, a high supercooling favors the appearance of graphite type D or E. This supercooling may result either from overheating of the liquid or from the increase of the cooling rate. Some studies ${ }^{[14,}$ ${ }^{38]}$ indicated that the titanium addition in gray cast iron generates the germination of small equiaxed dendrites and increases the transition temperature of graphite from type A to type D, which promotes type D graphite formation to low supercooling. Okada et al. ${ }^{[39]}$ suggested that titanium carbide formation (TiC) caused depletion of the carbon content in the solid/liquid interface, thus promoting the graphite formation of type D. Niobium, in surface addition, probably contributed to the structural changes of gray cast iron. According to the addition rate of niobium (1wt.\% \&3wt.\%), the morphology of graphite gradually changes in the matrix of type B to type E passing through type D. In agreement with previous studies ${ }^{[40]}$, niobium, according to the addition process used in this work, can act in various ways. Since the carbide formation energy is much smaller than that of the sulfides, and due to its high affinity to carbon, niobium may first form carbides. This leads to a local impoverishment of carbon in

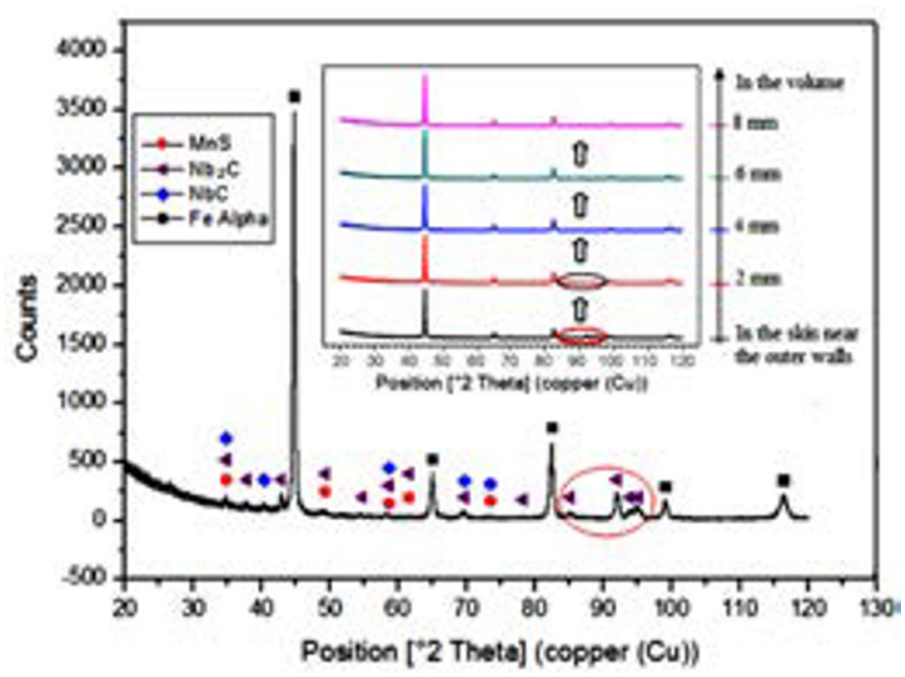

Fig. 5: Cast iron X-ray diffraction patterns in different regions (The indexed spectrum is taken from the area near the lower wall of the footprint. The spectra superposition shows the attenuation of the carbide peaks (circled in red) of the wall towards the volume.) the liquid, which may favor the formation of graphite type $\mathrm{D}^{[5]}$. Effectively, given the high affinity of niobium for carbon, $\mathrm{Nb}_{2} \mathrm{C}$ and $\mathrm{NbC}$ carbides are formed in the skin near the outer walls, revealed by XRD analysis point by point with a step of $2 \mathrm{~mm}$ (Fig. 5). Since their formation, they can act as heterogeneous nucleation sites for graphite in the eutectic reaction and for the sulfides, these latter provide graphite nucleation sites. Moreover, the undissolved $\mathrm{Fe}-\mathrm{Nb}$ also favors germination of $\mathrm{MnS}$ and $(\mathrm{Mn}, \mathrm{Fe}) \mathrm{S}$ sulphides (Fig. 6, Table 2), which induces an increase in the growth rate due to the multiplication of germination sites and the type B graphite transition to type E occurring. Consequently, increasing the number of graphite nucleation sites results in a refined graphite morphology. Moreover, according to Wenbin Zhou et al. ${ }^{[41]}$, niobium can also act as a retarder to the movement of carbon particles during solidification, which also limits the growth of graphite.

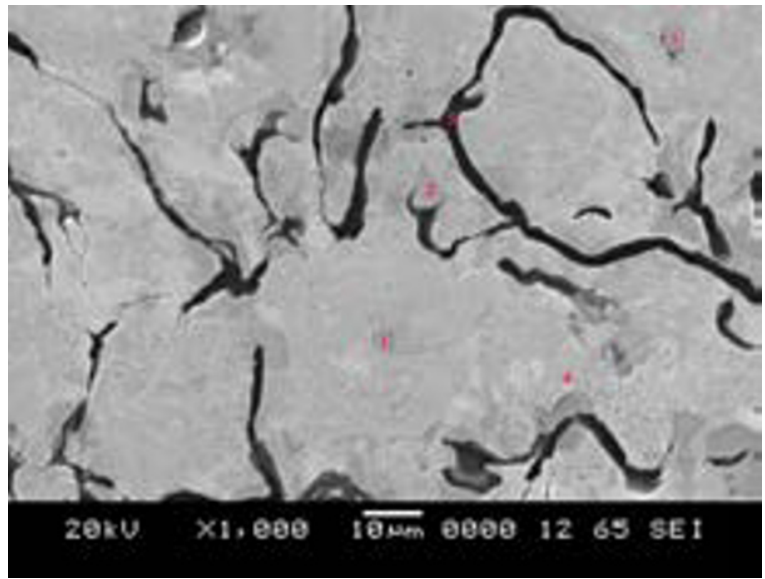

Fig. 6: SEM-EDXS analysis of non-metallic particles from cast iron sample with $1 \mathrm{wt} . \% \mathrm{Nb}$

Moreover, the addition of niobium contributes to an increase in the cooling rate as indicated in Fig. 7. At a high temperature $\left(1,350^{\circ} \mathrm{C} / 870^{\circ} \mathrm{C}\right.$.), the cooling rate of $7{ }^{\circ} \mathrm{C} \cdot \mathrm{s}^{-1}$ in the cast iron without addition increases to 9 ${ }^{\circ} \mathrm{C} \cdot \mathrm{s}^{-1}$ in the cast iron with $1 \mathrm{wt} . \%$ of $\mathrm{Nb}$ and to $10^{\circ} \mathrm{C} \cdot \mathrm{s}^{-1}$ in the cast iron with $3 \mathrm{wt} . \%$ of $\mathrm{Nb}$, which necessarily induce the supercooling of the eutectic liquid.

\section{Electrochemical behavior of lamellar gray cast iron}

\subsection{Niobium effect}

According to Nernst's theory, no metal is truly insoluble, and all metals tend to pass into solution. If a ferrous alloy electrode is immersed in a solution (alkaline, basic, acid or salt), some iron atoms yield their valence electrons and $\mathrm{Fe}^{2+}$ ions enter into solution. This will generate an excess of negative charge on the metal electrode. A potential difference then exists between the ferrous alloy and the solution. This process continues until the balance is established. 
Table 2: Chemical analysis by EDXS analysis of EN-GJL 250 cast iron with $1 \mathrm{wt} . \% \mathrm{Nb}$ (wt.\%)

\begin{tabular}{|c|c|c|c|c|c|c|c|c|c|}
\hline & \multicolumn{8}{|c|}{ Chemical element (wt.\%) } & \multirow{2}{*}{ Phase } \\
\hline & $\mathrm{Fe}$ & C & Si & Mn & $\mathbf{P}$ & $\mathbf{s}$ & $\mathrm{Cr}$ & $\mathrm{Nb}$ & \\
\hline 1 & - & - & - & 53.9 & - & 38.7 & - & 3.4 & $(\mathrm{Mn}, \mathrm{Nb}) \mathrm{S}$ \\
\hline 2 & 3.2 & - & - & 63.2 & - & 33.6 & - & - & $(\mathrm{Mn}, \mathrm{Fe}) \mathrm{S}$ \\
\hline 3 & - & - & - & 65.1 & - & 34.9 & - & - & MnS \\
\hline 4 & 91.7 & - & 0.4 & - & 6.9 & - & 0.9 & 0.1 & $\alpha-F e$ \\
\hline 5 & 06 & 94 & - & - & - & - & - & - & Graphite \\
\hline
\end{tabular}

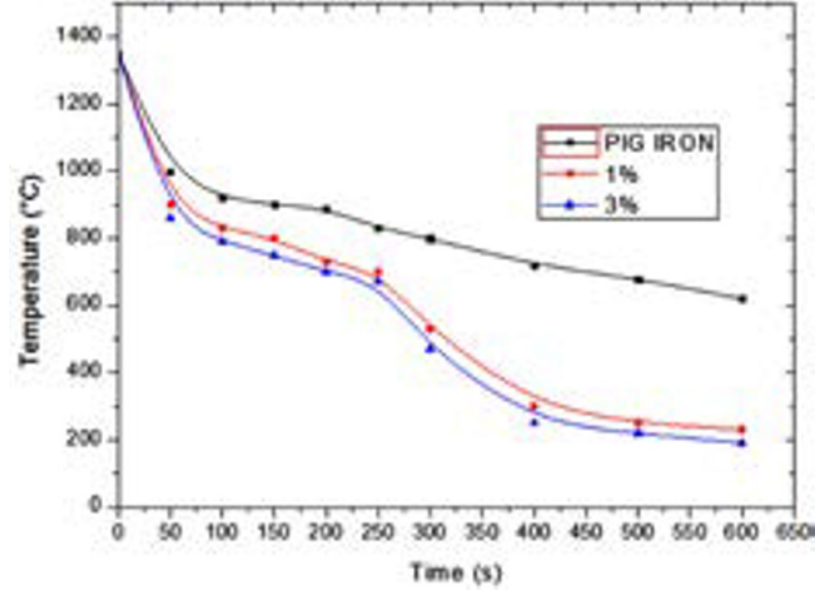

Fig. 7: Time-temperature cooling curves

In order to study the impact of niobium addition on the lamellar gray cast iron EN-GJL250 matrix, the samples were immersed in a $3.5 \mathrm{wt} . \% \mathrm{NaCl}$ solution.

Electrochemical polarization studies were carried out in a standard round-bottomed polarization cell. The potential of the working electrode was measured using the saturated calomel electrode (SCE). All the potentials mentioned in this work are in reference to SCE. All the potentiodynamic polarization studies were carried out after stabilization of the free corrosion potential. The scan rate used was $0.166 \mathrm{mV} \cdot \mathrm{s}^{-1}$. The corrosion rate was determined using the method of extrapolation of Tafel straight lines.

The polarization curves illustrated in Fig. 8 consist of two anodic and cathodic branches. The shape of these two branches and the two Tafel lines determine both the corrosion current and the corrosion potential. Depending on the direction of scanning from the cathodic polarization zone, the projection of intersection point of the two Tafel lines on the axis of the potentials gives the corrosion potential $E_{\mathrm{c}}$, which corresponds to the zero corrosion current.

The anode part of the polarization curve (Fig. 8) shows a continuous increase in current as a function of the potential. The shape of the anode branch of the curve $E=f(\log i)$ reveals a continuous dissolution of the base element (iron) which passes into solution by abandoning its negative charge according to the oxidation reaction (Eq. 2):

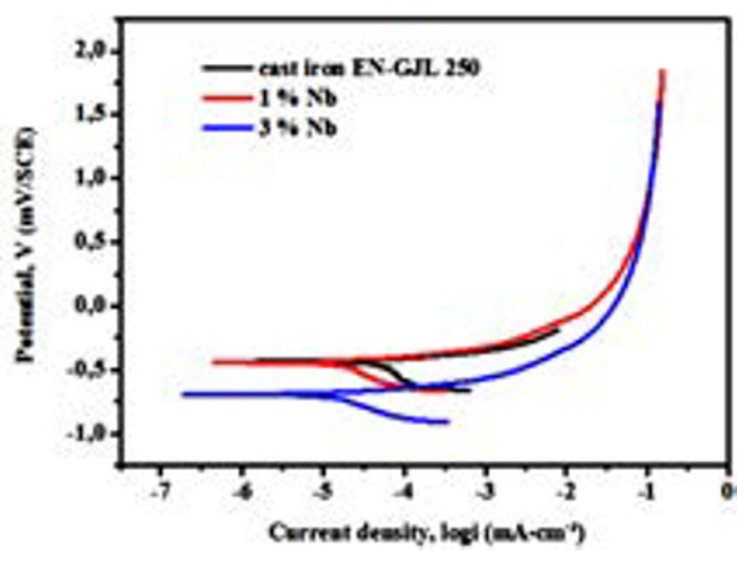

Fig. 8: Polarization curves of EN-GJL250 gray cast iron with and without $\mathrm{Nb}$ addition obtained in $3.5 \mathrm{wt} . \% \mathrm{NaCl}$ solution

$$
\mathrm{Fe} \Longleftrightarrow \mathrm{Fe}^{2+}+2 \mathrm{e}^{-}
$$

The niobium addition does not modify the cathodic part of the two polarization curves (samples containing $1 \mathrm{wt} . \% \mathrm{Nb}$ and $3 w t . \% \mathrm{Nb}$ ). For the sample with $1 \mathrm{wt} . \% \mathrm{Nb}$, the anode portion shape does not change from that of EN-GJL250 cast iron, it has just moved slightly to the left. Therefore, the corrosion potential slightly moves to negative values. On the other side, the appearance of the anodic part of the sample with 3wt.\% $\mathrm{Nb}$ is shifted to the right compared to the EN-GJL250 cast iron without addition. The corrosion potential in this case is shifted to negative values. Furthermore, the calculations of the different corrosion parameters determined jointly from corrosion VersaStudio software, by extrapolation of Tafel and linear polarization curves are summarized in Table 3.

The quantitative evaluations of the electrochemical parameters mentioned in Table 3 show that the values of the corrosion potentials of EN-GJL250 gray cast iron with the addition of $1 \mathrm{wt} . \%$ and $3 \mathrm{w} . \mathrm{t} \%$ of niobium are shifted towards more electronegative values of 10 and $261 \mathrm{mV}$, respectively, compared to that of gray cast iron EN-GJL250 without addition. Otherwise, niobium addition had the effect of reducing three times the corrosion current density. This leads to a considerable increase in the polarization resistance $R_{\mathrm{p}}$ of 125.89 to 291.38 Ohms, which is inversely proportional to the variation in the corrosion current density. Furthermore, the polarization 
Table 3: Parameters of electrochemical corrosion of samples with $1 \mathrm{wt} . \% \mathrm{Nb}$ and $3 \mathrm{wt} . \% \mathrm{Nb}$ in $3.5 \mathrm{wt} . \% \mathrm{NaCl}$ solution

\begin{tabular}{|c|c|c|c|c|c|c|}
\hline Samples & $\begin{array}{c}I_{\text {corr }} \\
\left(\mu \mathrm{A} \cdot \mathrm{cm}^{-2}\right)\end{array}$ & $\begin{array}{c}E_{\text {corr }}(l=0) \\
\text { (mV vs. SCE) }\end{array}$ & $\begin{array}{c}\boldsymbol{\beta}_{\mathrm{c}}(\mathrm{mV} / \mathrm{decade} \\
\text { vs. SCE })\end{array}$ & $\begin{array}{c}\beta_{\mathrm{a}}(\mathrm{mV} / \mathrm{dec} \text { dede } \\
\text { vs. SCE })\end{array}$ & $\begin{array}{c}R_{\mathrm{p}} \\
\text { (Ohms) }\end{array}$ & $\begin{array}{c}C_{r} \\
\left(m m \cdot y^{-1}\right)\end{array}$ \\
\hline $\begin{array}{l}\text { Cast iron } \\
\text { EN-GJL } 250\end{array}$ & 47.51 & -431.10 & 466.05 & 49.19 & 125.89 & 71.13 \\
\hline 1wt.\% Nb & 16.07 & -441.10 & 309.52 & 47.27 & 273.03 & 35.58 \\
\hline $3 w t . \% N b$ & 14.46 & -692.99 & 270.92 & 55.55 & 291.38 & 72.01 \\
\hline
\end{tabular}

resistance increases proportionally with the increase in the niobium addition fraction.

\subsection{Effect of inclusions}

The metallographic observations of the corroded samples can contribute to understanding the nature of corrosion process on EN-GJL250 gray cast iron with the addition of niobium in the $3.5 \mathrm{wt} . \% \mathrm{NaCl}$ solution. In order to preserve the integrity of the corroded surfaces for SEM analysis, no mechanical polishing was carried out.

The topographic observation by SEM-BSE (Fig. 9) reveals a deterioration of gray cast iron inclusions interfaces [(graphite, sulfides)/pearlitic matrix] by localized corrosion (pitting) which takes the form of an erosion corrosion.

As the corrosion of EN-GJL250 gray cast iron occurs by pitting, it seems to depend on the length, the size and the distribution of inclusions, in particular for the graphite. The longer the graphite lamellae, the higher the corrosion rate. The morphology of graphite can therefore significantly modify the corrosion behavior of cast iron. Furthermore, it not only depends on the number of germination sites, but also on the abundance of carbon in the melt. The addition of carbide-forming element such as niobium directly affects its evolution. Thus, the addition of niobium has a direct relation to morphology and fraction of the graphite which determine the effective cathodic area for the reduction reaction ${ }^{[43]}$. Azim and Sanad ${ }^{[4]]}$ have shown that current $I_{0}$ and the corrosion rate or corrosion current $I_{\text {corr }}$ increase in ascending order from the malleable cast iron, nodular cast iron and graycast iron. This can be explained by the areas of different graphite morphologies which increase in the same order. Since graphite has a higher potential in the galvanic series, near silver and gold, it acts as a cathodic site ${ }^{[45]}$.

Moreover, the SEM observations (Fig. 9) indicated that the pearlite matrix dissolves around the graphite, and the affected regions have the same shape as the cathode site (inclusions). In addition, the pearlitic matrix corrodes at the cementite/ferrite interfaces. Thus, the process of degradation of the matrix begins with the dissolution of the ferrite lamellae.

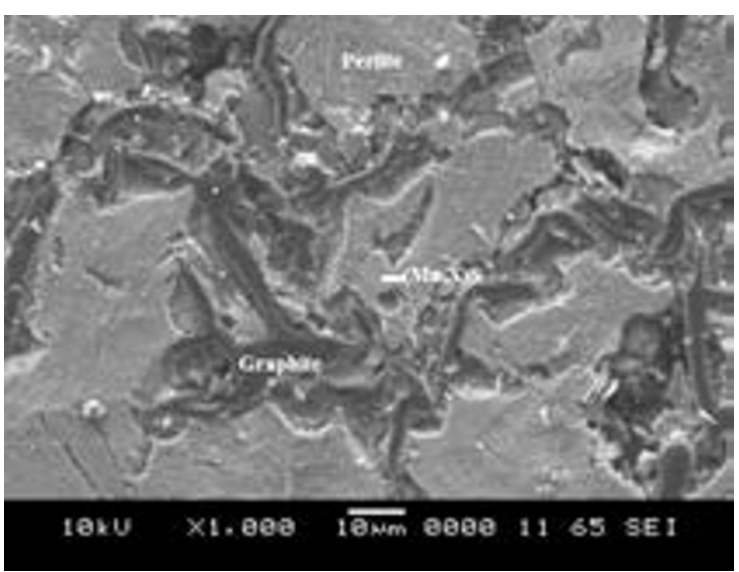

Fig. 9: SEM-BSE micrographs after corrosion test of EN-GJL250 cast iron sample with $1 \mathrm{wt} . \% \mathrm{Nb}$.

\section{Conclusions}

This work investigated the effect of niobium additions, at two proportions (1wt.\% and 3wt.\%), on the microstructural changes and electrochemical behaviour of EN-GJL250gray cast iron. The following conclusions can be drawn from the present study:

(1) The addition of niobium transformed the microstructure of gray cast iron from cellular structure to fully dendritic structure.

(2) Low-level niobium addition (1wt.\%) refined the eutectic cells from $300 \mu \mathrm{m}$ to $150 \mu \mathrm{m}$, probably owing to the increased germination sites.

(3) Undissolved ferro-niobium in combination with magnesium and sulphur ( $\mathrm{Mn}, \mathrm{Fe}) \mathrm{S}$ acted as a germination site for graphite.

(4) Niobium addition contributed to refine the graphite lamellae, by local depletion of carbon in the matrix near the wall, due to the formation of niobium carbides $\left(\mathrm{Nb}_{2} \mathrm{C}, \mathrm{NbC}\right)$, detected by XRD.

(5) Niobium addition reduced the corrosion current density by three times and increased the polarization resistance, $R_{\mathrm{p}}$.

(6) Polarization resistance increased proportionally by increasing the proportion of niobium addition.

Table 4: Morphological evolution of graphite and size of sulphurous inclusions on the analysed area by SEM-SE

\begin{tabular}{ccccc}
\hline Samples & $\begin{array}{c}\text { Graphite surface fraction } \\
(\%)\end{array}$ & $\begin{array}{c}\text { Graphite length } \\
(\mu \mathrm{m})\end{array}$ & $\begin{array}{c}\text { Graphite thickness } \\
(\mu \mathrm{m})\end{array}$ & $\begin{array}{c}\text { Sulfurous size } \\
\left(\boldsymbol{\mu} \mathbf{m}^{2}\right)\end{array}$ \\
\hline Cast iron EN: GJL-250 & 12.53 & 45 & 2.77 & 29.91 \\
1wt.\% Nb & 10.24 & 25 & 1.78 & 18.34 \\
3wt.\% Nb & 9.53 & 15 & 1.97 & 18.6
\end{tabular}




\section{References}

[1] Balachandran G, Vadiraj A, Kamaraj M, Kazuya E. Mechanical and wear behavior of alloyed gray cast iron in the quenched and tempered and austempered conditions. Materials \& Design, 2011 32 (7): 4042-4049.

[2] de Almeida L H, Ribeiro A F, Le May I. Microstructural characterization of modified $25 \mathrm{Cr}-35 \mathrm{Ni}$ centrifugally cast steel furnace tubes. Materials Characterization, 2002, 49 (3): 219-229.

[3] Kesri R, Durand-Charre M. Phase equilibria, solidification and solid-state transformations of white cast irons containing niobium. Journal of Materials Science, 1987, 22 (8): 2959-2964.

[4] Filipovic M, Kamberovic Z, Korac M, Gavrilovski M. Microstructure and mechanical properties of $\mathrm{Fe}-\mathrm{Cr}-\mathrm{C}-\mathrm{Nb}$ white cast irons. Materials \& Design, 2013, 47: 41-48.

[5] Alonso G, Stefanescu D, Larra naga P, et al. Solidification of superfine graphite iron revealed by interrupted solidification experiments. International Journal of Cast Metals Research, 2016, 29 (5): 258-265.

[6] Riposan I, Chisamera M, Stan S, et al. A new approach to graphite nucleation mechanism in gray irons. In Proceedings of the AFS Cast Iron Inoculation Conference, September 2005: 29-30.

[7] Lunarska E. Effect of graphite shape on the corrosion of grey cast iron in phosphoric acid. Materials and Corrosion, 1996, 47 (10): 539-544.

[8] Gelfi M, Gorini D, Pola A, et al. Effect of titanium on the mechanical properties and microstructure of gray cast iron for automotive applications. Journal of Materials Engineering and Performance, 2016, 25 (9): 3896-3903.

[9] Davis J R, Ed., ASM Specialty Handbook-Stainless Steels. ASM International, 1994.

[10] Collini L, Nicoletto G, Konecna R. Microstructure and mechanical properties of pearlitic gray cast iron. Materials Science and Engineering : A, 2008, 488 (1): 529-539.

[11] Murakami T, Inoue $\mathrm{T}$, Shimura $\mathrm{H}$, et al. Damping and tribological properties of $\mathrm{Fe}-\mathrm{Si}-\mathrm{C}$ cast iron prepared using various heat treatments. Materials Science and Engineering A, 2006, 432 (1): 113-119.

[12] Riposan I, Chisamera M, Stan S, et al. Three-stage model for nucleation of graphite in grey cast iron. Materials Science and Technology, 2010, 26 (12): 1439-1447.

[13] Riposan I, Chisamera M, Stan S, et al. Role of lanthanum in graphite nucleation in grey cast iron. Key Engineering Materials, Trans Tech Publ, 2011, 457: 19-24.

[14] Moumeni E, Stefanescu D M, Tiedje N S, et al. Investigation on the effect of sulfur and titaniumon the microstructure of lamellar graphite iron. Metallurgical and Materials Transactions A, 2013, 44 (11): 5134-5146.

[15] Sommerfeld A, Tonn B. Nucleation of graphite in cast iron melts depending on manganese, sulphur and oxygen. International Journal of Cast Metals Research, 2008, 21(1-4): 23-26.

[16] Muhmond H M, Fredriksson H. Relationship between inoculants and the morphologies of $\mathrm{MnS}$ and graphite in gray cast iron. Metallurgical and Materials Transactions B, 2013, 44 (2): 283-298.

[17] Goodrich G, Oakwood T, Gundlach R. Manganese, sulfur and manganese-sulfur ratio effects in gray cast iron. Transactions of the American Foundry Society and the One Hundred Seventh Annual Castings Congress, 2003: 783-812.

[18] Fra's E, G'orny M. Mechanism of dissolved sulfur influence on the transition from graphite to cementite eutectic in cast iron. Key Engineering Materials, Trans Tech Publ, 2011, 457: 137-142.

[19] Mehra R, Soni A. Cast iron deterioration with time in various aqueous salt solutions. Bulletin of Materials Science, 2002, 25 (1): 53-58.

[20] Seidu S O, Owoeye S S, Owoyemi H T. Assessing the effect of copper additions on the corrosion behaviour of grey cast iron. Leonardo Electronic Journal of Practices and Technologies, 2015, 26: 49-58.

[21] Jami R I, Litin A K S. Inhibition of the pitting corrosion of grey cast iron using carbonate. Materiali in Tehnologije, 2006, 40 (1): 3.

[22] Saricimen H, Quddus A, Eid O A, et al. Corrosion behaviour of cast iron exposed to Arabian gulf environment. Anti-Corrosion Methods and Materials, 2011, 58 (6): 303-311.

[23] Atkinson K, Whiter J, Smith P, et al. Failure of small diameter cast iron pipes. Urban Water, 2002, 4 (3): 263-271.

[24] Yamamoto K, Mizoguti S, Nagano S, et al. Service life prediction of industrial pipe-line. Tetsu-to-Hagane, 1985, 71 (1): 121-126.

[25] Mohebbi H, Li C Q. Experimental investigation on corrosion of cast iron pipes. International Journal of Corrosion, 2011, Article ID 506501.

[26] Tronstad L, Sejersted J. The effect of sulphur and phosphorus on the corrosion of iron. Journal of the Iron and Steel Institute, 1933, 127: 425-436.

[27] Miyata $Y$, Kuwahara $Y$, Asakura S, et al. Anodic dissolution of spheroidal graphite castiron with different pearlite areas in sulfuric acid solutions. International Journal of Corrosion, 2013, Article ID741378.

[28] Behnam M J, Davami P, Varahram N. Effect of coolingrate on microstructure and mechanical properties of gray castiron. Materials Science and Engineering A, 2010, 528 (2): 583-588.

[29] Fràs $E$, G'orny $M$, Lopez $H$. Eutectic cell and nodule count in grey and nodular cast irons. Materials Science and Technology, 2007, 23 (9): 1109-1117.

[30] Mizoguchi T, Perepezko J. Nucleation behavior during solidification of cast iron at high undercooling. Materials Science and Engineering A, 1997, 226: 813-817.

[31] Pedersen K M, Tiedje N S. Undercooling and nodulecount in thin walled ductile iron castings. International Journal of Cast Metals Research, 2007, 20 (3):145-150.

[32] Riposan I, Chisamera M, Stan S, et al. Graphite nucleant (microinclusion) characterization in $\mathrm{Ca} / \mathrm{Sr}$ inoculated grey irons. International Journal of Cast Metals Research, 2003, 16 (1-3): 105-111.

[33] Zhou Jiyang. Colour Metallography of Cast Iron. China Foundry 2009, 6 (1): 57-69.

[34] Kawalec M, G'orny M. Alloyed white cast iron with precipitates of spheroidal vanadium carbides VC. Archives of Foundry Engineering, 2012, 12 (4): 95-100.

[35] Kiani-Rashid A R, Mostafapour M, Kaboli-Mallak S K, Babakhani A. The effect of cooling rate on bainite phase formation in austempered nickel-molybdenum gray cast iron. ISRN Materials Science, 2011, 2011, Article ID 923241.

[36] Chisamera M, Riposan I, Stan S, et al. Graphite nucleation control in grey cast iron. International Journal of Cast Metals Research, 2008, 21(1-4): 39-44.

[37] Park J, Verhoeven J.Transitions between type a flake, type D flake, and coral graphite eutectic structures in cast irons. Metallurgical and Materials Transactions A, 1996, 27 (9): 2740-2753.

[38] Nakae H, Fujimoto K. Influence of Ti on graphite morphological transition in flake graphite cast iron. Key Engineering Materials, Trans Tech Publ, 2011, 457: 25-30.

[39] Okada A, Miyake H. The unknown world of cast iron. KANSAI Univ Press, 1996: 141

[40] Zhi X, Xing J, Fu H, et al. Effect of niobium on the as-cast microstructure of hypereutectic high chromium cast iron. Materials Letters, 2008, 62 (6): 857-860.

[41] Zhou Wenbin, Zhu Hongbo, Zheng Dengke, et al. Niobium alloying effect in high carbon equivalent grey cast iron. Research \& Development, 2011: 36-40

[42] Zumelzu E, Cabezas C, Opitz O, et al. Microstructura characteristics and corrosion behaviour of high-chromium cast iron alloys in sugar media. Protection of Metals, 2003, 39 (2): 183-188.

[43] Vasudevan S, Raja V, Seshan S, Chattopadhyay K. Study of influence of manganese additions on electrochemical corrosion behaviour of austenitic spheroidal graphite iron. British Corrosion Journal, 1986, 21(2): 87-94.

[44] Azim A A, Sanad S. Effects of acid concentration, content and temperature on the corrosion rate of steel in $\mathrm{HCl}$. Corrosion Science, 1972, 12 (4): 313-324.

[45] Fontana M G. Corrosion Engineering. Tata McGraw-Hill Education, 2005. 